\title{
Descriptive epidemiology of stigma against depression in a general population sample in Alberta
}

Trevor M Cook ${ }^{1}$ and JianLi Wang*1,2

\begin{abstract}
Background: Mental health illnesses, such as depression, are responsible for a growing disease burden worldwide. Unfortunately, effective treatment is often impeded by stigmatizing attitudes of other individuals, which have been found to lead to a number of negative consequences including reduced help-seeking behavior and increased social distance. Despite the high prevalence of depression in Canada, little research has been conducted to examine stigma against depression in the Canadian general population. Such information is crucial to understanding the current state of stigmatizing attitudes in the Canadian communities, and framing future stigma reduction initiatives. The objectives of this study were to estimate the percentages of various stigmatizing attitudes toward depression in a general population sample and to compare the percentages by demographics and socioeconomic characteristics.
\end{abstract}

Methods: We conducted a cross-sectional telephone survey in Alberta, Canada, between February and June 2006. Random digit dialing was used to recruit participants who were aged 18-74 years old ( $n=3047)$. Participants were presented a case vignette describing a depressed individual, and responded to a 9-item Personal Stigma questionnaire. The percentages of stigmatizing attitudes were estimated and compared by demographic and socioeconomic variables.

Results: Among the participants, 45.9\% endorsed that depressed individuals were unpredictable and $21.9 \%$ held the view that people with depression were dangerous. Significant differences in stigmatizing attitudes were found by gender, age, education, and immigration status. A greater proportion of men than women held stigmatizing views on each stigma item. No consistent trend emerged by age in stigma against depression. Participants with higher levels of education reported less stigmatizing attitudes than those with less education. Participants who were not born in Canada were more likely to hold stigmatizing attitudes than those who were born in Canada.

Conclusion: In the general population, stigmatizing attitudes towards depression differ by demographic characteristics. Men, those with less education and immigrants should be the targets of stigma reduction campaigns.

\section{Background}

Major depression is a prevalent mental disorder in the general population and is a leading cause of disease burden [1]. The annual prevalence of major depression in Canada and in the United States was $4.8 \%$ and $6.8 \%$ in 2002 , respectively $[2,3]$. To reduce the disease burden, comprehensive interventional strategies including primary and secondary prevention are needed. However, these efforts are often impeded by stigma against mental

\footnotetext{
* Correspondence: jlwang@ucalgary.ca

1 Department of Community Health Sciences, Faculty of Medicine, University of Calgary, 3330 Hospital Drive NW, Calgary, Canada

Full list of author information is available at the end of the article
}

illness. Stigma towards mental illness may negatively affect individuals' willingness to seek help [4-6]. Other consequences of discrimination against people with mental illness include social distancing and exclusion $[7,8]$, exacerbation of patient burden caused by the illness [9], chronic social impairment [10], and reduced life satisfaction $[8,11]$. Thus, one of the mandates of the Mental Health Commission of Canada is to conduct a national campaign to reduce stigma against mental illness [12]. Despite the high prevalence of major depression in the general population, stigmatizing attitudes towards depression in the general population are not well studied. 
Moreover, there is a lack of descriptive information about stigma against depression. Such information is critical to our understanding about the current status of stigma in the community, and providing a basis for mental health promotion and stigma reduction initiatives.

Mental health research has revealed three types of stigma: self-stigma - one's response to their own mental illness [5,13]; personal stigma - one's attitude towards a person with mental illness; and perceived stigma - one's belief about another's attitudes toward a person with mental illness [13]. All three types of stigma should be the targets of anti-stigma campaigns. To facilitate the development of anti-stigma programs targeting the general population, our study focused on personal stigma against depression.

Previous studies have found that depression stigma varies across demographic groups [14,15]. Further, mental health stigma has been found to have strong cultural roots and strong cross-cultural variations in its prevalence [16-18]. One Australian study found that in adults aged 18 years and over, the proportions of people holding views of personal stigma against depression were significantly higher among men, those with less education, and those born overseas, while age was positively associated with depression stigma in linear regression models [14]. A qualitative Australian study found participants reporting high degrees of depression stigma when individuals were viewed to be responsible for their own mental illness, a threat, or undesirable company [19].

In Canada, the study conducted by Wang and colleagues $[15,20]$ found that men had a lower level of depression literacy [20] and were more likely to hold stigmatizing attitudes than women [15,21]. A higher level of education and being a health professional were negatively associated with depression stigma. In the Australian and the Canadian studies [14,15], the same Depression Stigma Scale, which is a dimensional scale, was used. As there is not a meaningful cutoff for the depression stigma scores, factors associated with the depression stigma scores were examined in linear regression modeling $[14,15]$. However, the beta coefficients in linear regression models are mathematical values and may not reflect important changes from clinical and public health perspectives. For example, what does a one or two point changes in the beta coefficient mean, and does the changes have significant meanings from the clinical and population health perspectives? In current analysis, we examined specific stigmatizing attitudes by demographic characteristics, providing more interpretable descriptive results about stigma against depression in the general population.

The objectives of this analysis were to (1) estimate the percentages of various stigmatizing attitudes towards depression in a general population sample, and (2) esti- mate and compare the percentages of various stigmatizing attitudes by demographic and socioeconomic characteristics.

\section{Methods \\ Study Population and Sampling}

From February to June 2006, we conducted a cross-sectional study examining depression literacy and stigma in Alberta, Canada. The target population was household residents in Alberta, aged 18 - 74 years old. Participants were recruited using random digit dialing method. Data was collected by interviewers of the Survey Unit of the Calgary Health Region (now Alberta Health Services), using the method of computer assisted telephone interview. Detailed information about sampling procedures can be found in previous publications $[15,20]$. This study was approved by the Conjoint Health Research Ethics Board of the University of Calgary. The final sample consisted of 3084 participants (response rate at the individual level $=75.2 \%$ ). Among the participants, 37 participants were excluded from this analysis as their ages did not fall between the study requirements (aged 18 - 74 years), likely due to data entry errors. In this analysis, 3047 participants were included.

\section{Depression Literacy Case Vignette}

In this study, we first presented a case vignette depicting a person (John or Mary) with major depression [15,20]. The case vignette is as follows:

"John is 30 years old. He has been feeling unusually sad and miserable for the last few weeks. Even though he is tired all the time, he has trouble sleeping nearly every night. John also doesn't feel like eating and has lost weight. He cannot keep his mind on his work and puts off making any decisions. Even day-to-day tasks seem too much for him. This has come to the attention of John's boss who is concerned about his lowered productivity."

After the case vignette, participants were asked "what would you say, if anything is wrong with John/Mary?" We used the answers to this question to determine whether participants could recognize depression. In the survey, we randomly used the name "John" and "Mary" to minimize potential bias related to gender of the person in the case vignette. Preliminary analysis revealed no significant difference in responses based on the name of the person depicted in the case vignette.

\section{Personal Stigma}

We administered a 9-item personal depression stigma scale, reflecting the personal attitudes towards John or Mary. This scale was developed by Griffiths and colleagues [22]. For each question in our study (and the original scale), respondents answered using a 5-point Likert scale - strongly agree, agree, neither agree nor disagree, 
disagree, and strongly disagree. The depression stigma scale in our study yielded a Cronbach's alpha of 0.715, which was close to that of Griffiths et al. $($ alpha $=0.76)$ [22]. In our analysis, we combined "strongly agree" and "agree" for each item to indicate the presence of personal stigma [13]. Additionally, we summed the score of each item to derive a total stigma score. In our study, the total stigma scores ranged from 0 to 34, with a higher score indicating a higher level of stigma.

\section{Demographic and Socioeconomic Variables}

Demographic and socioeconomic data was collected on all participants, including gender, education, age, employment status, immigration status, income, marital status, areas of residence (urban or rural), and whether or not participants were a health professional, or mental health professional. We classified participants into four groups by age (18-24 years old, 25 - 54 years old, 55 - 64 years old, $65-74$ years old). These categories are commonly used in psychiatric epidemiological studies. The age categorization was based on the facts that people of age 18 and 24 years old are considered young adults; the ages from 25 to 54 years are adulthood; between 55 and 64 years, biological changes are prominent, especially for women; those aged 65 and over are considered seniors. Education was split into three groups based on educational institution attended: (1) attended or completed high school, (2) attended or completed college, and (3) attended or completed university or higher education. Employment status was determined as whether or not the respondent had worked in a job or business in the previous week. Immigration status was determined by their self report of whether or not they were born in Canada. Annual personal income was split into four groups: (1) Those with an annual income less than $\$ 30000$, (2) those with an annual income between $\$ 30000$ and $\$ 60000$, (3) those who earned $\$ 60000-\$ 80000$ annually and (4) those who earned more than $\$ 80000$ annually. As personal income is a sensitive issue, we did not ask for the exact annual income, rather we asked in which of the previously described income groups their income would fit. Marital status was classified as (1) married or commonlaw, (2) single and never married, and (3) divorced, separated, or widowed. We considered participants' area of residence as urban area if they resided, worked, or were attending school in Calgary or Edmonton (urban), or rural area if they lived, worked, or attended school elsewhere in Alberta.

\section{Analysis}

The percentages of stigmatizing attitudes of the 9-item stigma scale were estimated. The percentages were then compared by demographic and socioeconomic characteristics using Chi square $\left(\mathrm{X}^{2}\right)$ tests. We conducted multivar- iate linear regression modeling to examine the relationships between the demographic and socioeconomic variables and total stigma scores. We first examined possible effect modifications by gender and other variables. If an effect modification was found, the associations between selected variables and stigma scores were estimated separately in men and women. The analyses were weighted to account for the effects of differential sampling probability, household size, number of telephone line and gender-age distribution of the general population in Alberta. As we compared the percentages for 9 different items in the bivariate analysis, we set the significance level at 0.005 . The analysis was conducted using STATA 10.0 [23].

\section{Results}

The weighted and un-weighted demographic and socioeconomic characteristics of the participants can be found in previous publications $[15,20]$. The overall and gender specific percentages of various stigmatizing attitudes towards depression are presented in Table 1. Overall, unpredictability emerged as the most prevalent stigmatizing view of depression, with $45.9 \%$ of participants reporting that they believed the person with depression in the case vignette to be unpredictable. This was followed by the refusal to vote for depressed individuals (39.5\%), not wishing to employ individuals suffering from depression (22.1\%), depressed individuals being dangerous $(21.9 \%)$, that people with depression could "snap out of it" if they wanted (16.7\%), and that they would not tell others of their depression (13.6\%).

Men reported higher proportions of stigmatizing attitudes than women on all items, except in their views of the depressed person as dangerous. In some stigmatizing attitudes, such as whether or not John or Mary should be avoided, the difference between men and women was only $3.4 \%$, while $18.2 \%$ more of men than women reported that they would not vote for a politician if they knew the person was depressed $\left(48.4 \%\right.$ versus $30.2 \%, X^{2}$ $(1)=102.02, p<0.001)$. Men were more than twice as likely as women to believe that individuals suffering from depression could "snap out of it" (23.4\% to $10.3 \%, \chi^{2}(1)=$ $90.48, \mathrm{p}<0.001)$ or should be avoided $\left(4.8 \%\right.$ to $1.4 \%, \chi^{2}(1)$ $=29.08, \mathrm{p}<0.001)$. It is also worth noting that over half $(57.8 \%)$ of male respondents reported that depressed individuals were unpredictable, compared to $42.2 \%$ of female participants $\left(\chi^{2}(1)=15.63, \mathrm{p}<0.005\right)$.

Table 2 contains age specific percentages of stigmatizing attitudes among the participants. As seen from the table, the trends were not consistent across items. When asked if depressed individuals could "snap out" of their illness, the percentages of stigmatizing attitude decreased with age $\left(x^{2}(3)=28.17, p<0.005\right)$. Conversely, when asked if they would not vote for a politician if they knew 
Table 1: Percentages of various stigmatizing attitudes overall and by gender*

\begin{tabular}{|c|c|c|c|c|c|}
\hline \multirow[t]{2}{*}{ Stigma Item } & \multirow[t]{2}{*}{$\begin{array}{c}\text { Overall } \\
n=2987\end{array}$} & \multicolumn{2}{|c|}{$\begin{array}{c}\text { Gender } \\
\text { (Weighted \%) }\end{array}$} & \multirow[t]{2}{*}{$x 2(1)$} & \multirow[t]{2}{*}{$P=$} \\
\hline & & $\begin{array}{c}\text { Male } \\
n=1525\end{array}$ & $\begin{array}{c}\text { Female } \\
n=1462\end{array}$ & & \\
\hline $\begin{array}{l}\text { People with a } \\
\text { problem like }(x) \text { 's } \\
\text { could snap out of } \\
\text { it, if they wanted." }\end{array}$ & 17.00 & 23.4 & 10.3 & 90.48 & $<0.001$ \\
\hline $\begin{array}{l}\text { "A problem like } \\
\text { (x)'s is a sign of } \\
\text { personal } \\
\text { weakness..." }\end{array}$ & 9.8 & 13.6 & 5.9 & 50.64 & $<0.001$ \\
\hline $\begin{array}{l}\text { "(x)'s problem is } \\
\text { not a real medical } \\
\text { illness..." }\end{array}$ & 8.5 & 11.3 & 5.7 & 29.64 & $<0.001$ \\
\hline $\begin{array}{l}\text { "People with a } \\
\text { problem like (x)'s } \\
\text { are dangerous." }\end{array}$ & 21.9 & 22.2 & 21.5 & 0.23 & $n / s$ \\
\hline $\begin{array}{l}\text { "It is best to a } \\
\text { avoid people with } \\
\text { a problem like } \\
\text { (x)'s..." }\end{array}$ & 3.2 & 4.8 & 1.4 & 29.08 & $<0.001$ \\
\hline $\begin{array}{l}\text { "People with a } \\
\text { problem like }(\mathrm{x}) \text { 's } \\
\text { are } \\
\text { unpredictable..." }\end{array}$ & 45.9 & 57.8 & 42.2 & 15.63 & $<0.005$ \\
\hline $\begin{array}{l}\text { "If I had a problem } \\
\text { like (x)'s, I would } \\
\text { not tell anyone." }\end{array}$ & 13.6 & 16.1 & 11.1 & 16.07 & $<0.001$ \\
\hline $\begin{array}{l}\text { "I would not } \\
\text { employ someone } \\
\text { if I knew they had } \\
\text { a problem like } \\
\text { (x)'s." }\end{array}$ & 22.1 & 29.1 & 14.7 & 87.68 & $<0.001$ \\
\hline $\begin{array}{l}\text { "I would not vote } \\
\text { for a politician if I } \\
\text { knew they had a } \\
\text { problem like (x)'s." }\end{array}$ & 39.5 & 48.4 & 30.2 & 102.02 & $<0.001$ \\
\hline
\end{tabular}

the person had depression, the percentages increased with age $\left(\mathrm{X}^{2}(3)=35.53, \mathrm{p}<0.001\right)$. With respect to whether depression was a real medical illness, those over 65 and under 24 years old were more likely to endorse that depression was not a real illness, compared to those aged $25-64\left(15 \% \& 12.1 \%\right.$ vs. $7.0 \% . X^{2}(3)=26.75, \mathrm{p}<$ $0.005)$.

The estimated percentages of stigmatizing attitudes by educational levels are in Table 3. Significant differences by educational levels were found in 5 of 9 stigma-related questions. Participants who were at the higher educational level were less likely to report that "X could snap out of it" (13.0\% versus $\left.22.8 \%, X^{2}(2)=37.15, p<0.001\right)$, "a problem like X's is a sign of personal weakness" (6.8\% versus $\left.13.0 \%, X^{2}(2)=21.84, P<0.005\right)$, "X's problem is not a real medical illness" $\left(5.9 \%\right.$ versus $13.5 \%, \mathrm{X}^{2}(2)=47.25, \mathrm{p}<$ $0.001)$, "People with a problem like X's are dangerous" $\left(14.9 \%\right.$ versus $\left.27.8 \%, X^{2}(2)=48.45, p<0.001\right)$ and "People with a problem like X's are unpredictable" (38.7\% versus $\left.53.0 \%, \chi^{2}(2)=40.23, p<0.001\right)$. Educational levels were not related to other stigmatizing attitudes.

Participants who were not born in Canada were more likely to report stigmatizing attitudes than those who were born in Canada on 5 out of 9 questions (see Table 4). When compared to individuals born in Canada, individuals not born in Canada were more likely to endorse that 
Table 2: Percentages of various stigmatizing attitudes by age*

\begin{tabular}{|c|c|c|c|c|c|c|}
\hline \multirow[b]{2}{*}{ Stigma Item } & \multicolumn{4}{|c|}{ Age (Weighted \%) } & \multirow[t]{2}{*}{$X 2(3)$} & \multirow[t]{2}{*}{$P=$} \\
\hline & $\begin{array}{c}18-24 \\
n=548\end{array}$ & $\begin{array}{c}25-54 \\
n=1203\end{array}$ & $\begin{array}{c}55-64 \\
n=1024\end{array}$ & $\begin{array}{c}65-74 \\
n=211\end{array}$ & & \\
\hline $\begin{array}{l}\text { People with a } \\
\text { problem like } \\
\text { (x)'s could } \\
\text { snap out of it, } \\
\text { if they } \\
\text { wanted." }\end{array}$ & 22.0 & 18.9 & 12.6 & 14.0 & 28.17 & $<0.005$ \\
\hline $\begin{array}{l}\text { "A problem } \\
\text { like }(\mathrm{x}) \text { 's is a } \\
\text { sign of } \\
\text { personal } \\
\text { weakness..." }\end{array}$ & 11.5 & 10.6 & 7.2 & 13.7 & 14.29 & $n / s$ \\
\hline $\begin{array}{l}\text { "(x)'s problem } \\
\text { is not a real } \\
\text { medical } \\
\text { illness..." }\end{array}$ & 12.1 & 7.0 & 7.0 & 15.0 & 26.75 & $<0.005$ \\
\hline $\begin{array}{l}\text { "People with a } \\
\text { problem like } \\
\text { (x)'s are } \\
\text { dangerous." }\end{array}$ & 17.8 & 23.9 & 20.7 & 26.4 & 11.45 & $n / s$ \\
\hline $\begin{array}{l}\text { "It is best to a } \\
\text { avoid people } \\
\text { with a } \\
\text { problem like } \\
\text { (x)'s..." }\end{array}$ & 5.2 & 2.7 & 2.4 & 4.3 & 11.48 & $n / s$ \\
\hline $\begin{array}{l}\text { "People with a } \\
\text { problem like } \\
\text { (x)'s are } \\
\text { unpredictable. } \\
. . "\end{array}$ & 45.8 & 43.5 & 47.4 & 52.4 & 7.31 & $n / s$ \\
\hline $\begin{array}{l}\text { "If I had a } \\
\text { problem like } \\
\text { (x)'s, I would } \\
\text { not tell } \\
\text { anyone." }\end{array}$ & 10.4 & 14.5 & 13.6 & 17.1 & 7.96 & $n / s$ \\
\hline $\begin{array}{l}\text { "I would not } \\
\text { employ } \\
\text { someone if I } \\
\text { knew they had } \\
\text { a problem like } \\
\text { (x)'s." }\end{array}$ & 23.8 & 18.9 & 23.9 & 27.7 & 13.33 & $n / s$ \\
\hline $\begin{array}{l}\text { "I would not } \\
\text { vote for a } \\
\text { politician if I } \\
\text { knew they had } \\
\text { a problem like } \\
\text { (x)'s." }\end{array}$ & 32.7 & 37.5 & 42.6 & 54.4 & 35.53 & $<0.001$ \\
\hline
\end{tabular}

*Note: The responses "Strongly Agree" and "Agree" have been combined to indicate the presence of stigma. All chi square tests had three degrees of freedom. $n / s=$ not significant. 
Table 3: Percentages of various stigmatizing attitudes by educational levels*

\begin{tabular}{|c|c|c|c|c|c|}
\hline \multirow[b]{2}{*}{ Stigma Item } & \multicolumn{3}{|c|}{ Education (Weighted \%) } & \multirow[t]{2}{*}{$x^{2}(2)$} & \multirow[t]{2}{*}{$P=$} \\
\hline & $\begin{array}{c}\text { High School or } \\
\text { less } \\
n=971\end{array}$ & $\begin{array}{c}\text { College or } \\
\text { Technical School } \\
\text { attended } \\
n=1002\end{array}$ & $\begin{array}{c}\text { University } \\
\text { Attended } \\
n=1006\end{array}$ & & \\
\hline $\begin{array}{l}\text { People with a } \\
\text { problem like }(\mathrm{x}) \text { 's } \\
\text { could snap out of } \\
\text { it, if they wanted." }\end{array}$ & 22.8 & 15.3 & 13.0 & 37.15 & $<0.001$ \\
\hline $\begin{array}{l}\text { "A problem like } \\
(\mathrm{x}) \text { 's is a sign of } \\
\text { personal } \\
\text { weakness..." }\end{array}$ & 13.0 & 9.6 & 6.8 & 21.84 & $<0.005$ \\
\hline $\begin{array}{l}\text { "(x)'s problem is } \\
\text { not a real medical } \\
\text { illness..." }\end{array}$ & 13.5 & 6.1 & 5.9 & 47.25 & $<0.001$ \\
\hline $\begin{array}{l}\text { "People with a } \\
\text { problem like (x)'s } \\
\text { are dangerous." }\end{array}$ & 27.8 & 23.1 & 14.9 & 48.45 & $<0.001$ \\
\hline $\begin{array}{l}\text { "It is best to a } \\
\text { avoid people with } \\
\text { a problem like } \\
\text { (x)'s..." }\end{array}$ & 4.4 & 2.8 & 2.3 & 8.10 & $\mathrm{n} / \mathrm{s}$ \\
\hline $\begin{array}{l}\text { "People with a } \\
\text { problem like }(x) \text { 's } \\
\text { are } \\
\text { unpredictable..." }\end{array}$ & 53.0 & 46.1 & 38.7 & 40.23 & $<0.001$ \\
\hline $\begin{array}{l}\text { "If I had a problem } \\
\text { like (x)'s, I would } \\
\text { not tell anyone." }\end{array}$ & 13.3 & 13.3 & 14.2 & 0.45 & $\mathrm{n} / \mathrm{s}$ \\
\hline $\begin{array}{l}\text { "I would not } \\
\text { employ someone } \\
\text { if I knew they had } \\
\text { a problem like } \\
\text { (x)'s." }\end{array}$ & 24.9 & 21.1 & 20.5 & 6.39 & $\mathrm{n} / \mathrm{s}$ \\
\hline $\begin{array}{l}\text { "I would not vote } \\
\text { for a politician if I } \\
\text { knew they had a } \\
\text { problem like }(x)^{\prime} \text { 's." }\end{array}$ & 43.1 & 40.3 & 35.1 & 13.45 & $\mathrm{n} / \mathrm{s}$ \\
\hline
\end{tabular}

*Note: The responses "Strongly Agree" and "Agree" have been combined to indicate the presence of stigma. All chi square tests had two degrees of freedom. $\mathrm{n} / \mathrm{s}=$ not significant.

individuals could "snap out" of their depression $(29.6 \%$ vs. $\left.15.1 \%, X^{2}(1)=50.12, \mathrm{p}<0.001\right)$; perceive depression as a sign of personal weakness $\left(26.0 \%\right.$ vs. $7.3 \%, X^{2}(1)=136.11$, $\mathrm{p}<0.001)$; or believe it best to avoid individuals with depression (9.0\% vs. $\left.2.3 \%, \mathrm{X}^{2}(1)=50.97, \mathrm{p}<0.001\right)$. Individuals born outside Canada were more likely to believe that depression was not a real medical illness $(17.6 \%$ vs. $\left.7.2 \%, X^{2}(1)=46.65, p<0.001\right)$, or that they would not vote for a candidate they knew to be depressed (47.5\% vs. $\left.38.3 \%, X^{2}(1)=11.91, p<0.005\right)$. The two groups were not significantly different in other stigmatizing attitudes (unpredictability, danger, employment, and notification of illness).

Neither employment status (working or not working), nor whether participants lived in a rural or urban setting were found to have significant differences with respect to the stigmatizing attitudes in bivariate analysis. Results are available upon request.

We found that participants with an annual income of $\$ 80,000$ or more were more likely to indicate they would not vote for an individual if they knew them to be depressed than those with an annual income below $\$ 30,000$ (46.5\% vs. $\left.33.5 \%, \chi^{2}(3)=23.41, p<0.005\right)$. Partic- 
Table 4: Percentages of various stigmatizing attitudes by immigration status*

\begin{tabular}{|c|c|c|c|c|}
\hline \multirow[b]{2}{*}{ Stigma Item } & \multicolumn{2}{|c|}{$\begin{array}{c}\text { Immigration Status } \\
\text { (Weighted \%) }\end{array}$} & \multirow[t]{2}{*}{$x^{2}(1)$} & \multirow[t]{2}{*}{$P=$} \\
\hline & $\begin{array}{l}\text { Born in Canada } \\
n=2599\end{array}$ & $\begin{array}{c}\text { Not Born in Canada } \\
\qquad n=\mathbf{3 8 7}\end{array}$ & & \\
\hline $\begin{array}{l}\text { People with a problem } \\
\text { like }(x) \text { 's could snap out } \\
\text { of it, if they wanted." }\end{array}$ & 15.1 & 29.6 & 50.12 & $<0.001$ \\
\hline $\begin{array}{l}\text { "A problem like }(x) \text { 's is a } \\
\text { sign of personal } \\
\text { weakness..." }\end{array}$ & 7.3 & 26.0 & 136.11 & $<0.001$ \\
\hline $\begin{array}{l}\text { "(x)'s problem is not a } \\
\text { real medical illness..." }\end{array}$ & 7.2 & 17.6 & 46.65 & $<0.001$ \\
\hline $\begin{array}{l}\text { "People with a } \\
\text { problem like (x)'s are } \\
\text { dangerous." }\end{array}$ & 21.7 & 22.7 & 0.19 & $n / s$ \\
\hline $\begin{array}{l}\text { "It is best to a avoid } \\
\text { people with a problem } \\
\text { like (x)'s..." }\end{array}$ & 2.3 & 9.0 & 50.97 & $<0.001$ \\
\hline $\begin{array}{l}\text { "People with a } \\
\text { problem like (x)'s are } \\
\text { unpredictable..." }\end{array}$ & 45.3 & 46.4 & 2.24 & $n / s$ \\
\hline $\begin{array}{l}\text { "If I had a problem like } \\
\text { (x)'s, I would not tell } \\
\text { anyone." }\end{array}$ & 14.0 & 11.5 & 1.81 & $n / s$ \\
\hline $\begin{array}{l}\text { "I would not employ } \\
\text { someone if I knew they } \\
\text { had a problem like } \\
\text { (x)'s." }\end{array}$ & 21.6 & 26.0 & 3.70 & $n / s$ \\
\hline $\begin{array}{l}\text { "I would not vote for a } \\
\text { politician if I knew they } \\
\text { had a problem like } \\
\text { (x)'s." }\end{array}$ & 38.3 & 47.5 & 11.91 & $<0.005$ \\
\hline
\end{tabular}

ipants who were married or in a common-law relationship (41.3\%) and those who were divorced, separated or widowed (43.8\%) indicated that they would not vote for a candidate with depression $\left(X^{2}(2)=16.87, \mathrm{p}=0.005\right)$. Only $33.1 \%$ of those who were single or never-married expressed a similar attitude. Marital status and income were not found to be correlated with other stigmatizing attitudes.

Among health professionals, 29.2\% indicated that they would not vote for a politician if they knew they were depressed, compared to $40.5 \%$ of those who were not health professionals $\left(\chi^{2}(1)=12.91, \mathrm{p}<0.005\right)$. Mental health professionals were less likely than non-mental health professionals to withhold their condition from others $(2.9 \%$ versus $13.8 \%)\left(\mathrm{X}^{2}(1)=5.76, \mathrm{p}<0.005\right)$.

In multivariate linear regression modeling $(\mathrm{F}=28.69, \mathrm{p}$ $<0.001)$, we found effect modifications between gender and case recognition $(\beta=-1.17$, standard error $=0.57, \mathrm{p}=$
$0.04)$ and between gender and immigration status $(\beta=$ 1.59 , standard error $=0.74, \mathrm{p}=0.03$ ). This indicated that, the relationship of gender on stigma scores was modified by case recognition, and by immigration status. Women participants who could recognize depression in the case vignette were more likely to have lower stigma scores, while women who were immigrants were likely to have higher stigma scores. As such, multivariate linear regression models were conducted in men and in women separately. The results of the multivariate linear regression modeling are in Table 5.

Gender specific regression modeling $(\mathrm{F}=8.06, \mathrm{p}<$ 0.001 in men, $\mathrm{F}=13.63, \mathrm{p}<0.001$ in women) showed that immigration status and income levels were positively associated with stigma in men; while educational levels, rural/urban residence and case recognition were negatively associated with stigma scores in men (Table 5). In women, immigration status was positively associated 
with stigma; educational levels, being a health professional and case recognition were negatively associated with stigma. This indicated that, while male and female immigrants were more likely to have high stigma scores than non-immigrants, the effect was more pronounced in women. Men with a higher income were more likely to have high stigma scores. Individuals with a higher level of education were less likely to have high stigma scores. Females who were health professionals were less likely to have high stigma scores. Men who lived in an urban setting were less likely to have high stigma scores. For both men and women the ability to recognize depression was associated with lower stigma scores, and this effect was more pronounced in women than men.

\section{Discussion}

This analysis provided descriptive information about personal stigma against depression in the general population of Alberta. One of the key findings was that $45.9 \%$ reported that "People with a problem like (x)'s are unpredictable" and $21.9 \%$ endorsed "People with a problem like $(\mathrm{x})$ 's are dangerous." We also found significant differences in stigma against depression by gender, age, educational levels and immigration status. The associations between case recognition, immigration status and stigma scores were stronger in women than in men.

Dangerousness, avoidance and character weakness are the main elements in the mechanism underlying stigma against mental illness [4]. These attitudes were reported by $21.9 \%, 9.8 \%$, and $3.2 \%$ of the participants respectively. It was unexpected that significant proportions of the participants held the views that "problem like John/Mary's is dangerous" and "persons with depression are unpredictable." These attitudes did not differ by age, however unpredictability differed by gender, and both differed by education. More studies are needed to investigate why the general public perceives people with depression as being dangerous and unpredictable. Results of such studies could have significant implications for stigma reduction.

Gender emerged as a significant factor associated with depression stigma. This was consistent with previous research indicating men had held higher stigmatizing attitudes than women [21]. Previous research has indicated that women have higher levels of depression literacy than men [15], and that increasing levels of mental health literacy is correlated with lower levels of depression stigma [20-22], therefore, the gender differences in

Table 5: Results of multivariate linear regression modeling of stigma, overall and by gender

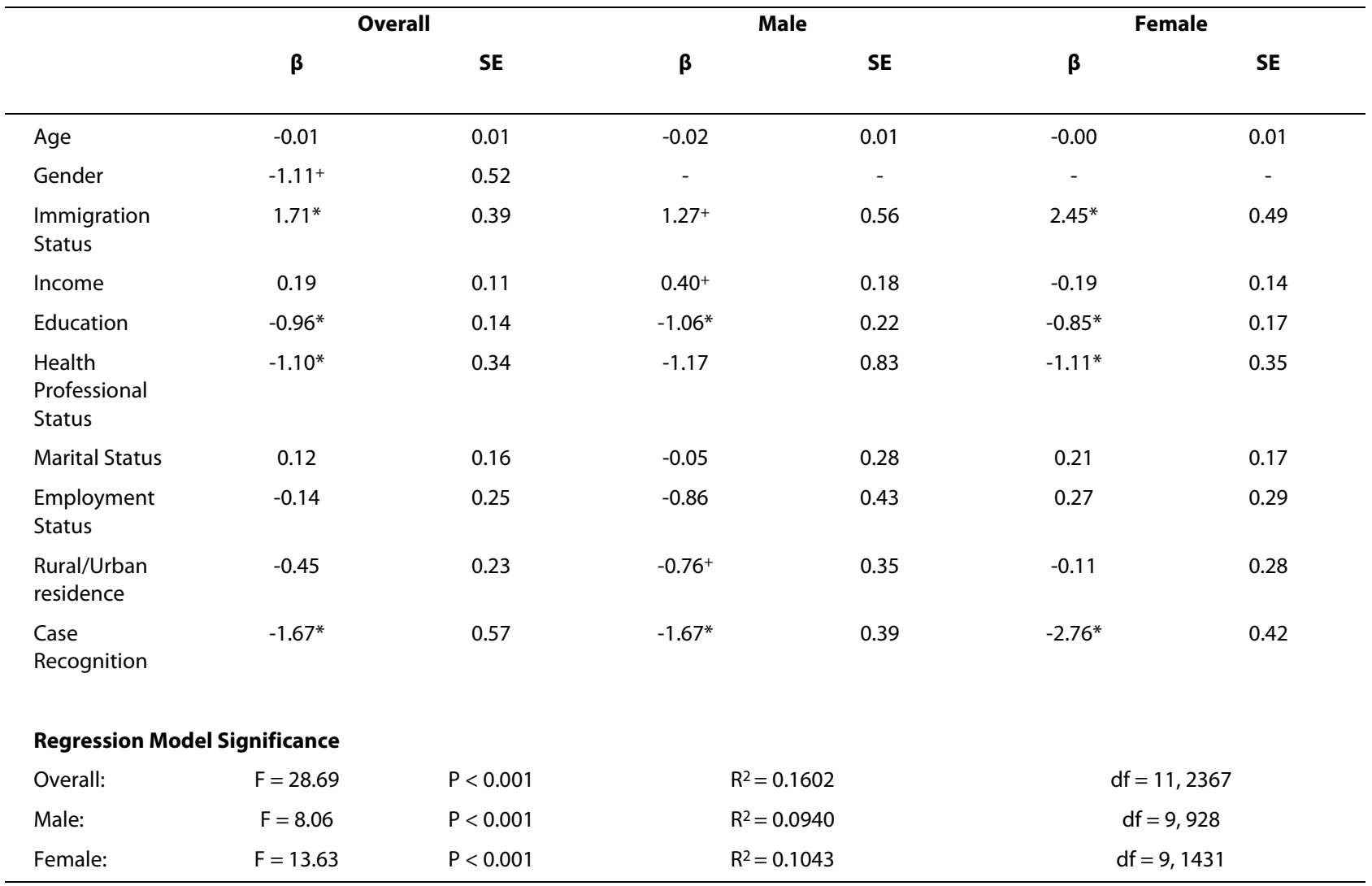

${ }^{*} p<0.005,{ }^{+} p<0.05$. SE $=$ Standard Error. 
the stigmatizing attitudes observed in this study were expected. This may also be due to observations that when compared to men, women are more likely to be exposed to depression [15], are three times more likely to experience a major depressive episode in response to certain events [24], and are twice as likely to be depressed [25] potentially due to different gender-related risk factors [26], and emotional experience and response [27]. Research in other mental illnesses has found contrary results however - a German study found woman to have higher stigmatizing attitudes than men when dealing with schizophrenic individuals [28], while others have found no gender difference at all in dealing with depression [29]. As a result, future research into mental health stigma should continue in order to gain insight into mental health literacy and search for potential influences on gender differences, where they exist.

Age differences existed in three of the nine items of depression stigma and three different trends emerged. This difference in trends makes it difficult to allow conclusions to be drawn regarding the influence of age on depression stigma. A study by Wolkenstein and Meyer [30] points to the potential impact of 'political correctness' on mental health attitudes, and the impact of this phenomenon on perceived social desirability [30]. It is reasonable to assume that attitudes of political correctness and perceptions of social desirability differ by age groups, in addition to education background. Future research into stigma against mental illness should therefore address both mental health literacy, as well as perceptions of social desirability.

Participants who were at the higher educational level were less likely to report stigmatizing attitudes than others, which was consistent with the Australian study [14]. Over half (53.0\%) of individuals who had only attended high school believed depressed individuals to be unpredictable, compared to only $38.7 \%$ of those who had attended University. When asked if these individuals were dangerous, the proportions were $27.8 \%$ to $14.9 \%$ for high school and university attendees respectively. The differences by educational levels suggest that in order to reduce fear in the general population towards individuals with depression, the messages may need to be tailored by people's educational levels. Nevertheless, the implications of the differences by educational levels need to be further investigated.

Our results found immigration status to be a major demographic variable in the examination of depression stigma. On certain stigma items, individuals not born in Canada were twice, three times, and in one case four times more likely to hold a stigmatizing attitude than those born in Canada. This is consistent with an Australian study that also found immigrants to hold higher stigmatizing attitudes [14]. A number of studies have also explored the impact of culture on depression stigma: Depression stigma has been found to be higher among Chinese Americans than White Americans [17], among White Americans than African Americans [16], and among older Korean Americans than younger Korean Americans [18]. These attitudes have been attributed to perceptions of family shame in Koreans [18], and a depression diagnosis as being "morally unacceptable" among Chinese Americans [31]. Further, it has been found that different cultural groups often experience different symptoms of depression, which may not only complicate diagnosis and mental health literacy, but also contribute to stigma against depression [31]. This is of particular concern given findings that the effectiveness of educational interventions is moderated and dependent upon an individual's beliefs about depression and its causation [32].

An unexpected result was the lack of difference in stigma between health and mental health professionals and the general public in most of the 9 items. Mental health professionals were found to differ only in their willingness to disclose their depression, and health professionals only in their willingness to vote for a depressed individual when compared to the general population. Health professionals are the group that mental health consumers deal with first when they seek health services. Therefore, reducing stigma in health professionals is critical. More research should be undertaken to further examine these relationships, as the ability of our analysis to draw meaningful calculations from these professional groups was limited by the small sample size of health professionals $(\mathrm{n}=348)$ and mental health professionals $(\mathrm{n}=$ 74) in our study.

Case recognition emerged as a significant factor in stigma against depression in linear regression modeling. Wang and colleagues reported that $75.6 \%$ of participants (85.5\% of women, $66.1 \%$ of men) of this study could correctly recognize depression in the case vignette [20]. The ability to recognize depression was associated with lower stigma, though this effect was more pronounced in women [20]. The results suggest that improving depression literacy may reduce stigma against depression. However, future large scale campaigns to promote depression should consider that depression literacy level in the population may be high. In our sample, the proportion of case recognition is $75.6 \%$. Therefore, there could be a "ceiling effect" in promoting depression literacy at the population level. Nevertheless, the levels of mental health literacy can be varied by regions. In our sample, $24.4 \%$ could not recognize the depression case vignette. As such, some may argue that the negative attitudes of these individuals cannot be deemed as "stigma against depression." This view may be debatable because the case vignette depicts a person with major depression and the 
attitudinal scale was conceptualized as stigma against depression by the developers. To certain extent, people's views on the person in the case vignette can be considered their attitudes towards depression. The difference in the meanings of "stigma against depression" in different groups should be considered in interpreting the results.

Our study provided the descriptive information about stigma against depression in a Canadian general population sample, which can be used to assist in planning stigma reduction programs in Canada. For example, based on data from consecutive surveys about stigma, comparing changes in overall stigma scores can provide information about the effectiveness of stigma reduction programs at the population level - whether or not the programs have had positive impacts on stigma; comparing changes specific items would yield information about changes in specific areas.

This study has several limitations. First, while efforts were made to correct for the number of participants in each household, number of telephone lines, and the sexage distribution of the province, it remained that only residential participants with a telephone were eligible for participation. The findings may be applicable to those who do not have telephone and those who are homeless. There existed the possibility for reporting and recall bias due to the study's reliance on self-reporting. Due to the cross-sectional nature of this study, only a correlation, and not a causal relationship, between variables can be established. Lastly, given the sample of this study was drawn from the Province of Alberta, it may not be possible to generalize this study to other populations.

\section{Conclusions}

Stigma against depression differs by gender, age, education, and immigration status. The findings that men reported more stigmatizing attitudes than women, and that those with higher levels of education would report lower levels of depression stigma is consistent with existing literature. It was unexpected that immigration status would be so strongly related to levels of depression stigma, or that there would be no clear relationship between depression stigma and participant age. Future studies need to better understand the mechanisms underlying stigma against depression in the subpopulations so as to develop effective strategies to reduce stigma.

\section{Competing Interests}

The authors declare that they have no competing interests.

\section{Authors' Contributions}

In the preparation of this paper, TMC was responsible for literature review, data analysis, manuscript preparation and submission. JLW was involved in manuscript preparation and interpretation. Both authors read and approved the final manuscript.

\section{Acknowledgements}

Funding for this study was provided by a grant from Alberta Innovates - Health Solutions (AlHS) (formerly the Alberta Heritage Foundation for Medical Research) to Dr. JianLi Wang. The Canadian Institutes of Health research (CIHR) also supports Dr. JianLi Wang through the New Investigator Award. Neither the AIHS nor the CIHR had any further role in this study, its design, data collection, data analysis and interpretation, writing, or decision for this and other publications.

\section{Author Details}

'Department of Community Health Sciences, Faculty of Medicine, University of Calgary, 3330 Hospital Drive NW, Calgary, Canada and 2Department of Psychiatry, Faculty of Medicine, University of Calgary, 3330 Hospital Drive NW, Calgary, Canada

Received: 4 June 2009 Accepted: 19 April 2010

Published: 19 April 2010

\section{References}

1. Üstün TB, Ayuso-Mateos JL, Chatterji S, Mathers C, Murray CJL: Global Burden of Depressive Disorders in the year 2000. British Journal of Psychiatry 2004, 184(5):386-392.

2. Kessler RC, Berflund P, Demler O, Jin R, Koretz D, Merikangas KR, Rush JA, Waters EE, Wang PS: The epidemiology of major depressive disorder: results from the National Comorbidity Survey Replication (NCS-R). Journal of the American Medical Association 2003, 289:3095-3105.

3. Patten SB, Wang JL, Williams JVA, Currie SR, Beck CA, Maxwell CJ, ElGuebaly NA: Descriptive Epidemiology of major depression in Canada. Canadian Journal of Psychiatry 2006, 51(2):84-90.

4. Rusch N, Angermeyer MC, Corrigan PW: Mental illness stigma: concepts, consequences, and initiatives to reduce stigma. European Psychiatry 2005, 20(8):529-539.

5. Barney L, Griffiths KM, Jorm AF, Christensen H: Stigma about depression and its impact on help seeking intentions. Australian and New Zealand Journal of Psychiatry 2006, 40(1):51-54.

6. Chandra A, Minkovitz CS: Stigma starts early: gender differences in teen willingness to use mental health services. Journal of Adolescent Health 2006, 38:e1-8.

7. Crisp AH, Gelder MG, Rix S, Meltzer HI, Rowlands OJ: Stigmatisation of people with mental illness. British Journal of Psychiatry 2000, 117:4-7.

8. Sirey JA, Bruce ML, Alexopoulos GS, Perlick DA, Raue P, Friedman SJ: Perceived stigma as a predictor of treatment discontinuation in young and older outpatients with depression. Am J Psychiatry 2001, 158:479-481.

9. Link BG, Struening EL, Rahav M, Phelan JC, Nuttbrock L: On stigma and its consequences: evidence from a longitudinal study of men with dual diagnoses of mental illness and substance abuse. Journal of Health and Social Behaviour 1997, 38:177-190.

10. An der Heiden $\mathrm{W}$, Häfner $\mathrm{H}$ : The epidemiology of onset and course of schizophrenia. European Archives of Psychiatry and Clinical Neuroscience 2000, 250:292-303.

11. Markowitz FE: The effects of stigma on the psychological well-being and life satisfaction of persons with mental illness. Journal of Health and Social Behaviour 1998, 39:335-347.

12. Kirby MJL, Keon WJ: Out of the shadows at last: transforming mental health, mental illness and addiction services in Canada. In Final report of the Standing Committee on Social Affairs, Science and Technology Ottawa $(\mathrm{ON})$ : The Senate Committee; 2006

13. Griffiths KM, Nakane Y, Christensen H, Yoshioka K, Jorm AF, Nakane H: Stigma in response to mental disorders: a comparison of Australia and Japan. BMC Psychiatry 2006, 6:21.

14. Griffiths KM, Christensen H, Jorm AF: Predictors of Depression Stigma. BMC Psychiatry 2008, 18:8-25.

15. Wang JL, Fick G, Adair C, Lai D: Gender specific correlates of stigma toward depression in a Canadian general population sample. Journal of Affective Disorders 2007, 103:91-97.

16. Givens J, Kalz I, Bellamy S, Holmes W: Stigma and the Acceptance of Depression Treatments Among African Americans and Whites. Journal if Internal Medicine 2007, 22(9):1292-1297.

17. Hsu LKG, Wan LM, Chang H, Summergrad P, Tsang BYP, Chen H: Stigma of depression is more severe in Chinese Americans than Caucasian 
Americans. Psychiatry: Interpersonal and Biological Processes 2008, 71(3):210-218.

18. Jang Y, Chiriboga D, Okazaki S: Attitudes towards mental health services: age-group differences in Korean American adults. Aging and Mental Health 2009, 13(1):127-134.

19. Barney LJ, Griffiths KM, Christensen H, Jorm AF: Exploring the nature of stigmatizing beliefs about depression and help seeking: Implications for reducing stigma. BMC Public Health 2009, 9(1):61.

20. Wang JL, Adair C, Fick G, Lai D, Evans B, Perry BW, Jorm A, Addington D: Depression literacy in Alberta: findings from a general population sample. Canadian Journal of Psychiatry 2007, 52(7):442-449.

21. Wang JL, Lai D: The relationship between mental health literacy, personal contacts and personal stigma against depression. Journal of Affective Disorders 2008, 110:191-196.

22. Griffiths KM, Christensen H, Jorm AF, Evans K, Groves C: Effect of webbased depression literacy and cognitive-behavioural therapy interventions on stigmatizing attitudes to depression: randomised controlled trial. British Journal of Psychiatry 2004, 185:342-249.

23. StataCorp: Stata Statistical Software: Release 10.0 Stata Corporation, College Station, TX; 2007.

24. Maciejewski P, Prigerson $H$, Mazure C: Sex differences in even-related risk for major depression. Psychological Medicine 2001, 31:593-604.

25. Wolk SI, Weissman MM: Women and depression: an update. In American Psychiatric Press Review of Psychiatry Volume 14. Edited by: Oldham J, Riba M. Washington DC: American Psychiatric Press; 1995:227-259.

26. Nolen-Hoeksema S, Girgus JS: The emergence of gender differences in depression during adolescence. Psychological Bulletin 1994, 115(3):424-443

27. Stapley J, Haviland J: Beyond depression: Gender differences in normal adolescents' emotional experience. Behavioral Sciences 1989, 20(56):1573-2762.

28. Gaebel W, Baumann A, Witte A, Zaeske H: Public attitudes towards people with mental illness in six German cities. European Archive of Psychiatry and Clinical Neuroscience 2002, 252:278-287.

29. Schnittker J: Gender and reactions to psychological problems: an examination of social tolerance and perceived dangerousness. Journal of Health and Social Behavior 2000, 44:224-240.

30. Wolkenstein L, Meyer T: Attitudes of young people towards depression and mania. Psychol Psychother-T 2008, 81:15-31.

31. Kleinman A: Culture and Depression. The New England Journal of Medicine 2004, 351:951-953.

32. Rusch LC, Kanter JW, Brondino MJ: A comparison of contextual and biomedical models of stigma reduction for depression with a nonclinical undergraduate sample. Journal of Nervous and Mental Disorders 2009, 197(2):104-110.

\section{Pre-publication history}

The pre-publication history for this paper can be accessed here: http://www.biomedcentral.com/1471-244X/10/29/prepub

\section{Submit your next manuscript to BioMed Central} and take full advantage of:

- Convenient online submission

- Thorough peer review

- No space constraints or color figure charges

- Immediate publication on acceptance

- Inclusion in PubMed, CAS, Scopus and Google Scholar

- Research which is freely available for redistribution

Submit your manuscript at www.biomedcentral.com/submit
C) Biomed Central 